\title{
Theoretical Approach Towards Rational Design and Characterization of Benzo[1,2-b:5-B']dithiophene (BDT)-Based (A-D-A) Small Molecules of Relevance for High Performance Solar Cells
}

Khlaifia D, Mestiri T, Mabrouk L and Kamel Alimi*

Unité de Recherche, Matériaux Nouveaux et Dispositifs Electroniques Organiques, Faculté des Sciences de Monastir, University of Monastir, 5000 Monastir, Tunisia

\begin{abstract}
Benzo[1,2-b:5-B']dithiophene (BDT)-based small molecules with acceptor-donor-acceptor (A-D-A) structure were designed based on the experimental system BDTT-S-TR (1) for use as potential donor materials for organic photovoltaic (OPV) devices. Their geometry structures, electronic properties and other key parameters related to OPVs such as absorption spectra, energetic driving forces $\Delta E_{L-L}$, power conversion efficiencies (PCEs) and intramolecular charge transfer properties have been investigated by means of density functional theory (DFT) and time dependent density functional theory (TDDFT) methods. These have been exploited as donor materials for a heterojunction with $[6,6]$ phenyl- $C_{71}$-butyric acid methyl ester $\left(\mathrm{PC}_{70} \mathrm{BM}\right)$ as acceptor material. Based on Marks model, an excellent agreement between the experimental and predicted $P C E$ was obtained for the reported system $1 / \mathrm{PC}_{70} \mathrm{BM}$ and a significant improvement in PCEs of BHJ devices based on 2-4/PC ${ }_{70} \mathrm{BM}$ was manifested. The charge transfer rates of the interfacial charge transfer $k_{\text {inter-CT }}$ and recombination $k_{\text {inter-CR }}$ in 1-4/PC ${ }_{70} \mathrm{BM}$ heterojunctions have been calculated using Marcus-Levich-Jortner rate equation. The calculations show that the ratios $k_{\text {inter-CT }} k_{\text {inter-CR }}$ for the 2-4/PC $\mathrm{P}_{70} \mathrm{BM}$ heterojunctions are $\sim 10^{4}$ times higher than that of the $1 / \mathrm{PC}_{70} \mathrm{BM}$. From these predictions, we reached our purpose to provide rational design of three novel molecules that will be more promising candidates for high-efficiency SMs OPVs materials.
\end{abstract}
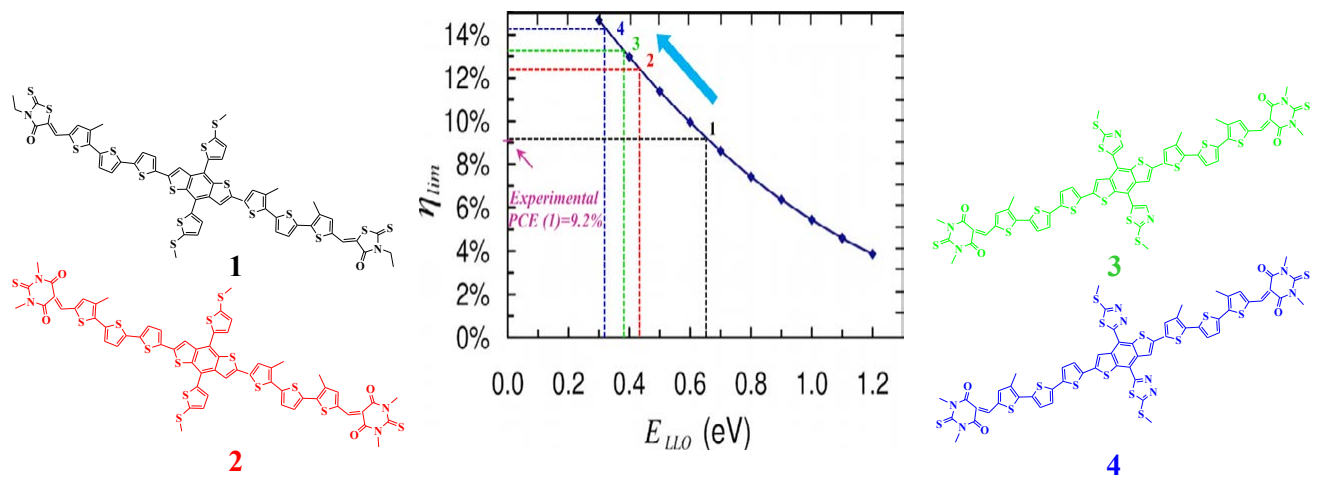

Keywords: Organic Photovoltaic; benzo[1,2-b:5-B']dithiophene (BDT); Acceptor-donor-acceptor; Small molecules; PCBM; DFT

\section{Introduction}

Organic photovoltaic cells (OPVs) have recently brought considerable attention to their potential to become an economically viable source of affordable, clean, and renewable energy. In the quest to improve the performance of polymer solar cells (PSCs), the distinction of the critical factors limiting their power conversion efficiency (PCE) with a view to rationalizing the relationship between the structures of the active layers, their morphology, and the electronic processes taking place at their interface is required. Following the groundbreaking work of Tang et al. [1], it is very well believed that the presence of a donor/ acceptor (D/A) interface in PSCs can significantly impact the dynamics of the charge carriers and facilitate the dissociation mechanism of excitons and most of the OPVs till date are fabricated with such a design. Bulk-heterojunction (BHJ) PSCs, where typically a conjugated polymer or a small molecule (SM) as an electron donor (D) is blended with fullerene derivative as an electron acceptor (A) into a favorable nanoscale phase-separated morphology, is the most prominent and successful PSCs device at present [2-4]. In principle process, the photo- generated excitons formed at the $\mathrm{D} / \mathrm{A}$ interface dissociate into bound electron-hole pairs forming charge transfer, which drift to be collected at separate electrodes to generate current. Cooperatively, these processes including the critical parameters to impact the performance of OPV calibrate the PCE of BHJ device [5-10].

Great progress has been achieved in both donor and acceptor

*Corresponding author: Kamel Alimi, Unité de Recherche, Matériaux Nouveaux et Dispositifs Electroniques Organiques, Faculté des Sciences de Monastir, University of Monastir, 5000 Monastir, Tunisia, Tel: 73500 276; E-mail: kamel.alimi@fsm.rnu.tn

Received November 17, 2017; Accepted February 05, 2018; Published February 15,2018

Citation: Khlaifia D, Mestiri T, Mabrouk L, Alimi K (2018) Theoretical Approach Towards Rational Design and Characterization of Benzo[1,2-b:5-B']dithiophene (BDT)-Based (A-D-A) Small Molecules of Relevance for High Performance Solar Cells. J Material Sci Eng 7: 423. doi: 10.4172/2169-0022.1000423

Copyright: ( 2018 Khlaifia D, et al. This is an open-access article distributed under the terms of the Creative Commons Attribution License, which permits unrestricted use, distribution, and reproduction in any medium, provided the original author and source are credited. 
Citation: Khlaifia D, Mestiri T, Mabrouk L, Alimi K (2018) Theoretical Approach Towards Rational Design and Characterization of Benzo[1,2-b:5-B'] dithiophene (BDT)-Based (A-D-A) Small Molecules of Relevance for High Performance Solar Cells. J Material Sci Eng 7: 423. doi: 10.4172/2169-0022.1000423

Page 2 of 10

materials development and device optimization, witnessed by the dramatic increase in devices PCEs from less than $2 \%$ before 2008 to over than $10 \%$ in recent years [11-15]. In this regard, fullerene and their derivatives have been extensively used as acceptor materials within BHJ devices because of their important electronic properties such as small reorganization energy, high electron mobility and affinity [16-18]. Nowadays $\pi$-conjugated small molecules (SMs) have attracted considerable research interest for OPVs, due to their great advantages over their polymers and copolymers counterparts, including low cost manufacturing, flexibility, light weight, and well-defined molecular structure [19-22]. Recently, record-high OPV efficiencies have been obtained by innovations of SMs donor materials. Among several designed SMs for solution processed solar cells, benzo[1,2-b:5-B'] dithiophene (BDT)-based SMs have been emerging as an attractive building block for donor molecules in OPVs. The BDT unit with a structural symmetry and rigid fused aromatic system can promote electron delocalization and cofacial $\pi-\pi$ stacking in the solid state, leading to highly ordered systems and thus high charge carrier mobilities. Today's PCEs near 10\% were demonstrated in OPVs using BDT-based solution processed SMs [23,24]. It deserves to mention here that high performance OPVs have also been designed using BDT containing polymers [24-28]. Lately, Li et al. [14] reported a linear acceptor-donor-acceptor (A-D-A) structured SM (BDTT-S-TR) with alkylthio-thienyl-substitued BDT (BDTT-S) as the core donor unit (D) and terthiophene end-capped with electron-withdrawing rhodanine (TR) as acceptor units (A). The synthesized molecule BDTT-S-TR (1) shows high solution processability, crystalline structure, broad absorption spectrum, good hole transport ability, and low-lying HOMO energy level [14,29-31]. The optimized OPV device based on BDTT-S-TR/PC ${ }_{70} \mathrm{BM}\left([6,6]\right.$ phenyl- $\mathrm{C}_{71}$-butyric acid methyl ester) (1/ $\mathrm{PC}_{70} \mathrm{BM}$ (Figure 1b)) exhibit high PCE of 9.2\% [14].

Herein, taking (1) as a reference, we have designed SM 2 through keeping the BDTT-S as the core donor unit and varying the number of nitrogen atoms in the end-capped group of the acceptor units (Figure 1). Previous studies have demonstrated that the crystalline character of BDT based D-A copolymers and SMs can be adjusted by increasing the number of nitrogen atoms in the acceptor unit $[32,33]$. Benefited from the good properties of SM 2, we have subsequently designed SMs 3 and 4 by retaining the core acceptor unit of 2 and modifying the core donor BDTT-S by substituting some carbon atoms by nitrogen atoms. Here, the introduction of nitrogen atoms in the donor unit is aimed to tuning the energy levels and thus lowering energy-gaps and broadening absorption spectra, which is expected to enhance the shortcircuit current $\left(J_{\mathrm{SC}}\right)$ and the open-circuit voltage $\left(V_{\mathrm{OC}}\right)$. Based on SM 4, we have designed the SM 5 by fluorination of the thiophene ring in the acceptor units. The geometric structures, electronic properties and other factors related to OPVs such as absorption spectra, driving forces $\Delta \mathrm{E}_{\mathrm{L}-\mathrm{L}}$, PCEs and intramolecular charge transfer properties of SMs 1-5 have been systematically evaluated using density functional theory (DFT) and time dependent density functional theory (TDDFT) methods. Furthermore, the charge transfer and charge recombination rates in $\mathrm{BHJ}$ OPVs based on $1-4 / \mathrm{PC}_{70} \mathrm{BM}$ have been predicted using Marcus Theory [34,35], which has been extensively used to probe the kinetic data for charge separation and recombination in D/A systems in OPVs.

\section{Computational Details}

The ground state of all investigated molecular systems in the current work such as $\mathrm{SMs} 1-5, \mathrm{PC}_{70} \mathrm{BM}$, and $1-4 / \mathrm{PC}_{70} \mathrm{BM}$ was investigated with DFT method. No initial symmetry constrains were applied. It is worthy to note that, to save the computational cost, we have replaced the alkyl-branched chain in designed SMs 1-5 with methyl groups, since it is proved that they possess no significant influence on the electronic and optical properties of the host materials [36-39]. To verify the benchmark of energy levels in OPV, we tested the functionals B3LYP [40], B3PW91 [41] and PBE0 [42] with 6-31G(d) basis set to calculate the highest occupied molecular orbital (HOMO) energy level for the SM 1 as a reference. The results listed in Table S1 (ESI) indicate that while B3LYP overestimates the $\mathrm{E}_{\text {номо }}$, both B3PW91 and PBE0 predict $\mathrm{E}_{\text {номо }}$ close to the experimental value (only $0.02 \mathrm{eV}$ difference). Therefore, to substantiate the reliability of the computational methods B3PW91 and PBE0, we need to examine the excited state of SM 1. Thus, based on DFT calculations (B3PW91 or PBE0), M06, M06X, CAM-B3LYP, WB97X(D), BHandHLYP as well as the ground state (a)

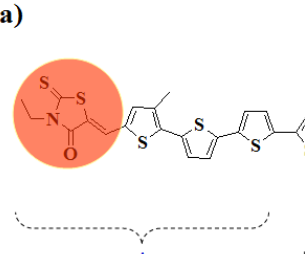

A

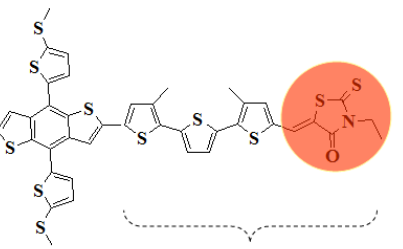

A

D

(1)

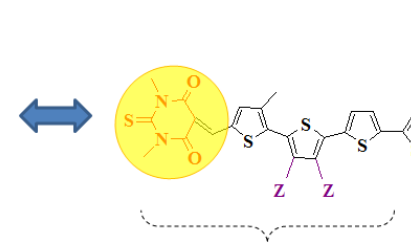

A

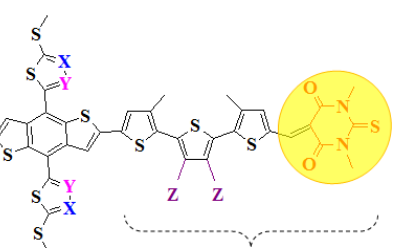

A

(b)

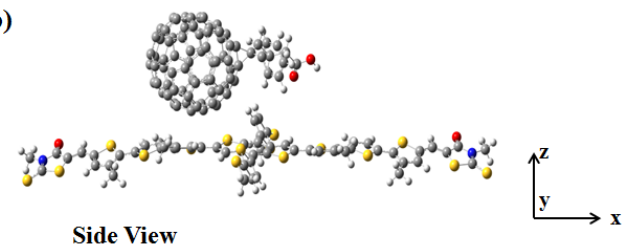

Figure 1: (a) Chemical structures of investigated SM 1 and designed SMs 2-5. The labels $A$ and D designed respectively the acceptor and the donor units in the molecule. (b) An interface model of the heterojunction molecule $1 / \mathrm{PC}_{70} \mathrm{BM}$ containing the $\mathrm{SM} 1$ as a donor and a single $\mathrm{PC} \mathrm{C}_{70} \mathrm{BM}$ molecule as an acceptor. 
Citation: Khlaifia D, Mestiri T, Mabrouk L, Alimi K (2018) Theoretical Approach Towards Rational Design and Characterization of Benzo[1,2-b:5-B'] dithiophene (BDT)-Based (A-D-A) Small Molecules of Relevance for High Performance Solar Cells. J Material Sci Eng 7: 423. doi: 10.4172/2169-0022.1000423

functional (B3PW91 or PBE0) with 6-31G(d) basis set were utilized to simulate the absorption spectra of SM 1 using TDDFT calculations. Chloroform was employed as solvent in the TDDFT calculations, within the polarizable continuum model (PCM) [43,44]. The calculated and experimental data are collected in Tables S2 and S3 (ESI). The results show that, whatever SM 1 is optimized with B3PW91 or PBE0, the WB97X(D) functional gives a maximum absorption wavelength in good accordance with the experimental value. However, the difference between the WB97X(D) simulated maximum absorption wavelength and experimental values is only $2 \mathrm{~nm}$ when the structure is optimized with B3PW91 functional in its ground state. Consequently, based on the B3PW91/6-31G (d) optimized geometries in chloroform solution, the absorption spectra and excited-state energies of the SMs 1-5 were examined by TDDFT/ WB97X(D)/6-31G(d) method.

The $1-4 / \mathrm{PC}_{70} \mathrm{BM}$ interfaces were simulated using the optimized geometries of the SMs 1-4 and $\mathrm{PC}_{70} \mathrm{BM}$. Each SM is placed in the vicinity of $\mathrm{PC}_{70} \mathrm{BM}$ at a distance of $3.5 \AA$ with the fullerene anchored with the electron accepting moiety of the SM and the benzene cycle is oriented parallel to the donor core. This specific donor/fullerene arrangement has been verified, using NMR analyses, as the preferred arrangement for the highest performing BHJ OPV materials [45]. The ground state geometries of $1-4 / \mathrm{PC}_{70} \mathrm{BM}$ were simulated at the $\mathrm{B} 3 \mathrm{LYP} / 6-31 \mathrm{G}(\mathrm{d})$ level which has been proved to be a very powerful method to simulate the polymer/fullerene heterojunctions [39]. Based on the B3LYP/6$31 \mathrm{G}$ (d) optimized geometries, absorption spectra and excited-state energies were evaluated at the TDDFT/CAM-B3LYP/6-31G (d) method. It is well accepted that this long-range-correlated functional is a reliable functional for describing the intermolecular charge transfer (inter-CT) excitations in the $\mathrm{D} / \mathrm{A}$ heterojunctions model [46-48]. The inter-CT excited states of the $1-4 / \mathrm{PC}_{70} \mathrm{BM}$ interfaces were examined via the charge density difference (CDD) maps as implemented in Multiwfn $3.3[49,50]$. All the above mentioned quantum chemical calculations were carried out using Gaussian 09, revision A.02 [51].

\section{Results and Discussion}

\section{A-D-A small molecules: Geometric and electronic structures}

As above mentioned, the ground state molecular geometries of SMs 1-5 were optimized at the B3PW91/6-31G(d) level with no symmetry constraints. The optimized structures with the torsion angles along the conjugated backbones are plotted in Figure S1 (ESI).

All the optimized structures show twist angles between A and D moieties close proximity to $21^{\circ}$ due to the existence of the alkyl chain in the thiophene of the acceptor core, as confirmed in our previous work [52]. It can be seen from the side view, that SM 1 deviate more from the coplanar architecture compared to the designed SMs 2-5. The dihedral angle between the methyl-thienyl group and the BDT is $\sim 56^{\circ}$ for SMs $1-3$, larger than $19^{\circ}$ for SMs 4 and 5 . This difference is the result of the limiting steric interactions provoked by the introduction of nitrogen atoms in donor core. In addition, twist angles between the thiophene rings in the acceptor moieties are the largest for SM $1\left(17^{\circ}\right.$ $\left.24^{\circ}\right)$; this is a consequence of the repulsion between the sulfur atom of the thiophene ring and the adjacent methylene promoting the rotation of the alkyl chain [52]. The twist angles of SMs 2-4 are smaller than that of $1\left(6^{\circ}-20^{\circ}\right)$. This difference, although quite small, might due to the intramolecular $\mathrm{H} \cdots \mathrm{O}$ attractive interactions in the end-capped groups in SMs 2-4, which are verified by the short distance between $\mathrm{H}$ and $\mathrm{O}$ atoms $(\sim 2.03 \AA$ ). However, SM 5 possesses a quasi-planar backbone conformation, with all thiophene rings coplanar to each other. Consistent with other reports [53], we believe that the origin of this planarization could be the intramolecular $\mathrm{S} \cdots \mathrm{F}$ attractive interaction, as the sulfur atom and the fluorine atom are in close proximity $(\sim 2.86$ $\AA$ ). As a consequence, it is reasonable to declare that SMs 2-5 exhibit a more linear structure as compared to that of SM 1, suggesting that the novel designed SMs have good planarity beneficial for providing high charge carrier mobilities [54].

It is well known that the performance in $\mathrm{BHJ}$ solar cells is closely affected by the frontier molecular orbitals (FMOs) (HOMO and LUMO (lowest unoccupied molecular orbital)) since they are involved in the generation of exciton, charge transfer, dissociation and exciton recombination. Thus, in order to gain insight into the charge separation ability in D/A interface, the HOMO and LUMO energy levels of SMs 1-5 and $\mathrm{PC}_{70} \mathrm{BM}$ were calculated and the results are summarized in Table 1. The experimental HOMO and LUMO energy levels of SM 1, obtained by cyclic voltammetry $(\mathrm{CV})$ experiment, are $-5.18 \mathrm{eV}$ and $-3.25 \mathrm{eV}$, respectively [14]. The calculated HOMO and LUMO energies of SM $1(-5.16 \mathrm{eV}$ and $-3.18 \mathrm{eV}$, respectively) are very close to the experimental values, proving that DFT/B3PW91/6-31G(d) appears as suited method to study molecular electronic structures. It is worth mentioning that, for SMs 1-5 and $\mathrm{PC}_{70} \mathrm{BM}$, the HOMO energies were evaluated at the B3PW91/6-31G(d), and in order to produce more accurate LUMO energies for these systems, we have adopted an indirect method of calculation by appending the HOMO energy to that of the first singlet excitation simulated using TDDFT. The reliability of this computational method has been successfully confirmed by Musgrave et al. [55] and by Nelson et al. [56].

Comparing 1 and designed SMs 2-5, it is clear that the substitution of end-capping groups (in 2-5), the introduction of nitrogen atoms (in $3-5$ ), and finally the introduction of electron-withdrawing fluorine (in 5) stabilized significantly the HOMO energies by about 0.06 to 0.30 $\mathrm{eV}$. This result denotes that the HOMO energy levels of the designed SMs 2-5, having more coplanar configuration across the backbone than 1 , are very close to the HOMO energy of an ideal polymer ( $5.4 \mathrm{eV}$ ), providing them with good long-term stability in air and their BHJ photovoltaic devices with high $V_{\mathrm{OC}}[32,57]$. However, the LUMO energy levels of the molecules $2-5$ are between $-3.40 \mathrm{eV}$ and $-3.57 \mathrm{eV}$, lower by about 0.26 to $0.39 \mathrm{eV}$ than that of 1 . Note that SMs 1-5 are calculated to have energetically destabilized LUMO's compared to that

\begin{tabular}{|c|c|c|c|c|c|c|c|c|}
\hline & \multicolumn{4}{|c|}{ Calculated in vacuum $(\mathrm{eV})$} & \multicolumn{3}{|c|}{ Experimental (eV) } & \multirow[t]{2}{*}{ Ref } \\
\hline & $\mathbf{E}_{\text {номо }}$ & $\mathbf{E}_{\text {Lumo }}$ & $E_{g}$ & $\Delta \mathrm{E}_{\mathrm{L}-\mathrm{L}}$ & $\mathbf{E}_{\text {номо }}$ & $E_{\text {Lumo }}$ & $E_{g}$ & \\
\hline 1 & -5.16 & -3.18 & 1.98 & 0.65 & -5.18 & -3.25 & 1.93 & [14] \\
\hline 2 & -5.22 & -3.40 & 1.82 & 0.43 & & & & \\
\hline 3 & -5.34 & -3.45 & 1.89 & 0.38 & & & & \\
\hline 4 & -5.38 & -3.51 & 1.87 & 0.32 & & & & \\
\hline 5 & -5.46 & -3.57 & 1.89 & 0.26 & & & & \\
\hline $\mathrm{PC}_{70} \mathrm{BM}$ & -5.80 & -3.83 & & & & & & \\
\hline
\end{tabular}

Table 1: HOMO and LUMO energy levels for SMs 1-5 and $\mathrm{PC}_{70} \mathrm{BM}$ as determined at the B3PW91/6-31G(d) level in vacuum. The experimental values for 1 [14] are included for reference. 
Citation: Khlaifia D, Mestiri T, Mabrouk L, Alimi K (2018) Theoretical Approach Towards Rational Design and Characterization of Benzo[1,2-b:5-B'] dithiophene (BDT)-Based (A-D-A) Small Molecules of Relevance for High Performance Solar Cells. J Material Sci Eng 7: 423. doi: 10.4172/2169-0022.1000423

of $\mathrm{PC}_{70} \mathrm{BM}$, which can positively impact the electrons transfer between the studied SMs and the electron-transport material $\left(\mathrm{PC}_{70} \mathrm{BM}\right)$.

The distribution patterns of the FMOs for SMs 1-5 are carried out at B3PW91/6-31G(d) level and the electronic density contours are shown in Figure 2. For all molecules, the electronic cloud distributions of HOMO's show typical feature with electron delocalization on the thiophene rings of the acceptor units and the core donor BDTT-S, and partially on the end-capping groups. The orbitals in the LUMO's are mainly located on the electron-deficient units and partially on the donor core BDTT-S for SMs 1-3. For 4 and 5, the LUMO's also reside at the side chains (alkylthio-thienyl groups) on the donor unit. These results display that the introduction of nitrogen atoms in positions $Y$ (Figure 1) has a slight impact on the LUMO distribution of 4 and 5. Interestingly, the larger extent of orbital delocalization of 4 and 5 can be understood geometrically, since they are the most planar i.e. the most conjugated (Figure 2).

A-D-A small molecules: Lowest excitation energies and intramolecular charge transfer

The ability to effectively absorb sunlight is a critical parameter for
BHJSCs performance. Since it is the main light absorber in BHJSCs, the overall aim of donor materials design is to increase and optimize their absorption coverage to maximize $J_{\mathrm{SC}}$. From this point of view, Figure 3 shows the absorption spectra of SMs 1-5 simulated at TDDFT/ WB97X(D)/6-31G(d) level of theory. Additionally, the dominant excited states vertical transition energies reported from the absorption maximum of SMs 1-5, their corresponding oscillator strengths, dominant excitation characters, and charge difference density (CDD) maps are shown in Table 2.

The results reveal that, for all molecules, the maximum absorption peaks with the largest oscillator strength originate from $S_{0} \rightarrow S_{1}$, which is principally attributed to the transition of electrons from HOMO to LUMO. It was found that, in low-energy region, the absorption spectra of the designed 2-5 are slightly red-shifted in comparison with 1 . The redshift in optical absorption for the designed 2-5 is due mainly to the substitution of end-capped groups, in particular, the introduction of more nitrogen and oxygen functional groups in molecular chain. The maximum absorption wavelengths are in the order of $4>2>3>5>1$. This trend is governed by the geometric and electronic properties of the designed molecules; indeed, it is well known that optical absorption
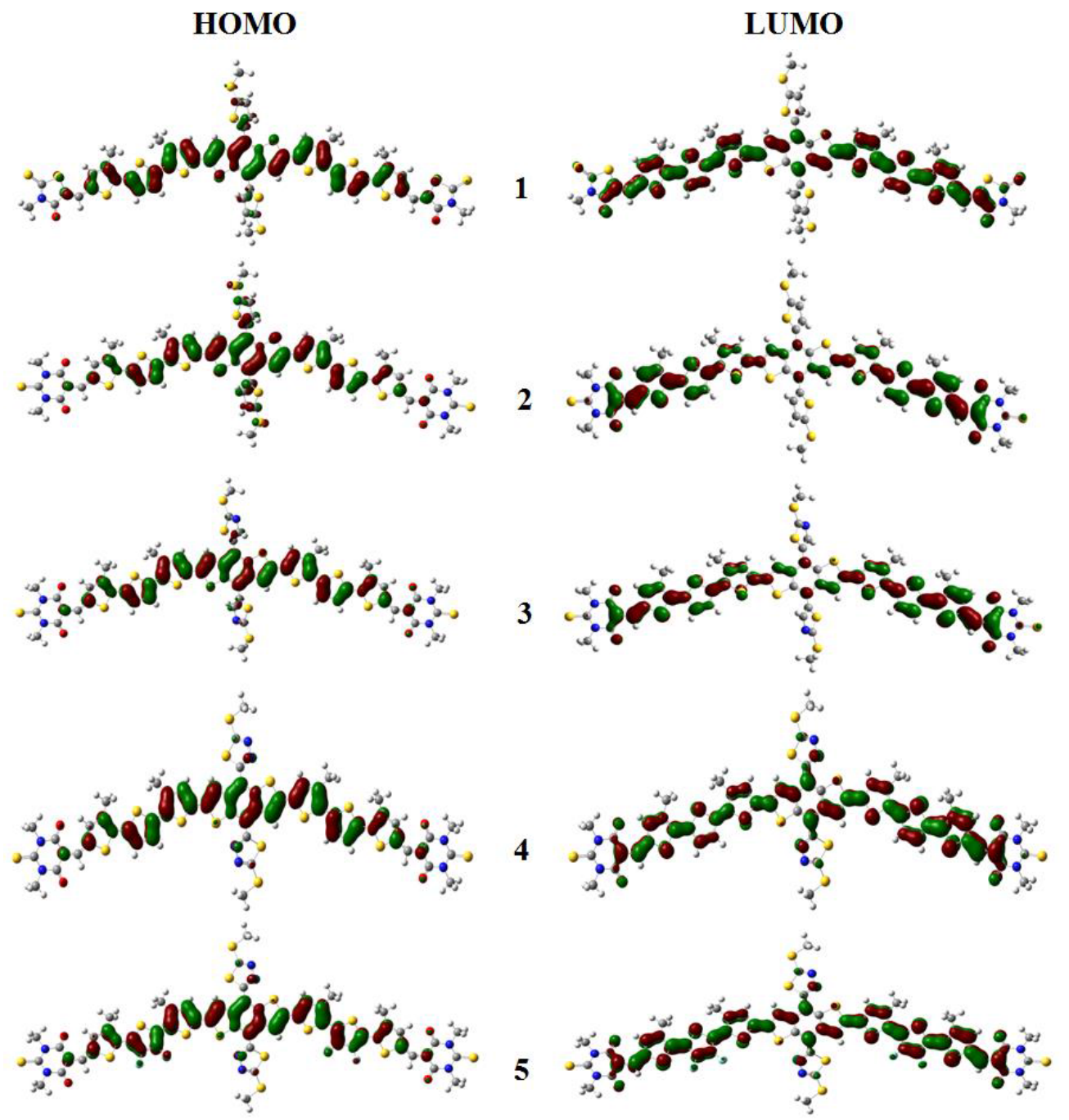

Figure 2: The distribution patterns of frontier molecular orbitals (FMOs) for SMs 1-5 carried out with DFT/B3PW91/6-31G (d) level. 
Citation: Khlaifia D, Mestiri T, Mabrouk L, Alimi K (2018) Theoretical Approach Towards Rational Design and Characterization of Benzo[1,2-b:5-B'] dithiophene (BDT)-Based (A-D-A) Small Molecules of Relevance for High Performance Solar Cells. J Material Sci Eng 7: 423. doi: 10.4172/2169-0022.1000423

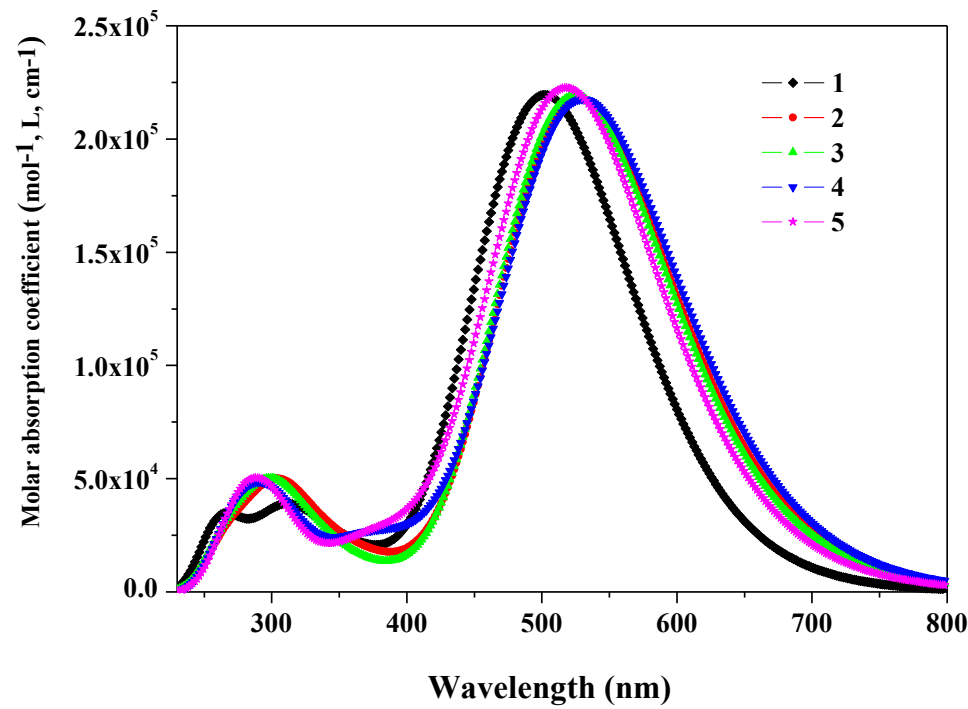

Figure 3: UV-Visible spectra of SMs 1-5 simulated at the TDDFT-PCM/WB97X(D)/6-31G(d)//DFT-PCM/B3PW91/6-31G(d) level of theory.

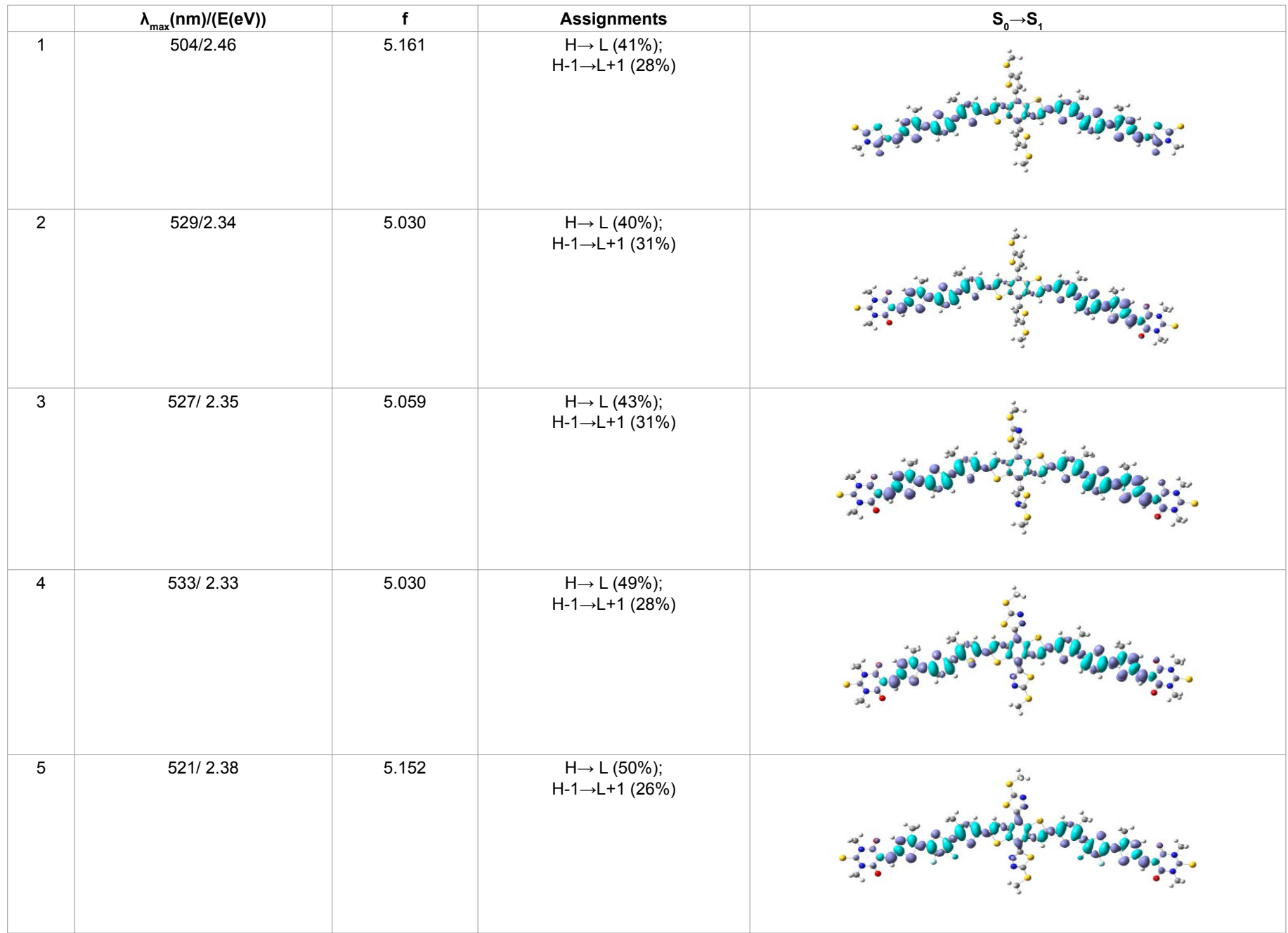

Table 2: Calculated maximum absorption wavelengths $\left(\lambda_{\max }(\mathrm{nm})\right)$, oscillator strengths (f) and dominant excitation character (H: HOMO, L: LUMO) and the charge density difference (CDD) maps (the violet and turquoise colors show increase and decrease in electron density, respectively) of low-lying singlet $\left(S_{0} \rightarrow S_{1}\right)$ states of $S M s$ 1-5. 
Citation: Khlaifia D, Mestiri T, Mabrouk L, Alimi K (2018) Theoretical Approach Towards Rational Design and Characterization of Benzo[1,2-b:5-B'] dithiophene (BDT)-Based (A-D-A) Small Molecules of Relevance for High Performance Solar Cells. J Material Sci Eng 7: 423. doi: $10.4172 / 2169-0022.1000423$

is sensible to the conformational planarity and electronic conjugation $[58,59]$. Compared to 1-3, 4 has the most red-shifted absorption, which is related to the more coplanar nature of the molecular structure. However, despite it is more planar than 4 , the maximum absorption of the fluorinated straight molecular chain (5) is slightly blue shifted in comparison with 2-4. The same effect has been reported by Martin et al. [53] for fluorinated thiophene-based polymers. High-energy absorption peaks of 1-5 appear at $297,303,305,308$, and $304 \mathrm{~nm}$, respectively, generated by the transitions of $S_{0} \rightarrow S_{12}$ for 1 and $S_{0} \rightarrow S_{10}$ for 2-5.

Intramolecular charge transfer (intra-CT) in 1-5 was visualized by CDD maps as shown in Table 2 to analyze the charge transfer properties in the major excited states $S_{0} \rightarrow S_{1}$. It is found that the maximum absorption bands in all systems are originated from an intra-CT between BDT unit of the core donor and the thiophene rings of the acceptor units. It can be seen that the contribution of BDT unit in electron transition increase in 4 and 5 since they are the most planar and then the most conjugated.

Therefore, the analysis of electronic and optical properties reveal that the designed SMs 2-5 possess broad and strong absorption, suitable FMO energy levels and high air-stability. The HOMO/LUMO overlap and the strong absorption of 2-5 are related to their geometries, since they are more planar and hence more conjugated than 1 . This would be helpful for enhancing their performances as excellent donor materials for OPVs, since the introduction of planar molecule with more extended $\pi$-conjugation can maximize the charge carrier mobility $[60,61]$.

\section{OPVs performance prediction: Marks model}

In the effort to direct scientists to design new materials and device structures, several empirical and theoretical models that describe limits to photovoltaic energy conversion in OSCs have been developed. Particularly, attention was paid to the absorption spectrum, the FMOs energy levels of donor and acceptor materials to estimate the opencircuit voltage $V_{\mathrm{OC}}$, and the driving force $\left(\Delta E_{L-L}\right)$ for efficient charge transfer.

Recently, in 2009, Marks et al. [62] advanced a practical efficiency limit of OPVs, where the J-V curve is assumed to be described by the classical diode model including series and parallel resistances. In their work, they treat the OPV efficiency as a function of LUMO offset $\left(\Delta E_{L-L}\right.$ ) by applying similar empirical estimate of the $V_{\mathrm{OC}}$ as Scharber et al. [63]. Indeed, they suggest that the $V_{\mathrm{OC}}$ is expressed in terms of the optical gap $E_{g}$ and the LUMO offset:

$$
V_{O C}=1 / e\left(E_{g}-\Delta E_{L-L}-0.3 \mathrm{~V}\right)
$$

where $e$ is the elementary charge, and $0.3 \mathrm{~V}$ is an empirical value for efficient charge separation $[63,64]$. Based on this assumption about the $V_{\mathrm{OC}}$, a practical efficiency limit of $\sim 14 \%$ is predicted for systems where the charge generation process occurs efficiently at $\Delta E_{L-L}=0.3-0.4 \mathrm{eV}$ [62].

According to the FMOs energy levels of the SMs 1-5 and $\mathrm{PC}_{70} \mathrm{BM}$ (Table 1), the energetic driving forces $\Delta E_{L-L}$ defined as the difference between the LUMO energy levels of SMs 1-5 and the $\mathrm{PC}_{70} \mathrm{BM}$ are calculated and listed in Table 1. The values for SMs 1-4 are 0.65, 0.43, 0.38 and $0.32 \mathrm{eV}$, respectively, which are all greater than $0.30 \mathrm{eV}$ ensuring a favorable forward electron transfer from donor to acceptor [62-64]. On the basis of these results, we deduce that the introduction of the endcapped group and nitrogen atoms allows for the tuning of FMOs of SMs 2-4 and make them more appropriate to serve as BHJSCs donors with $\mathrm{PC}_{70} \mathrm{BM}$ as an acceptor material. Nevertheless, the $\Delta E_{L-L}=0.26 \mathrm{eV}$ of SM 5 is lower than $0.30 \mathrm{eV}$, which denotes that the heterojunction based on $5 / \mathrm{PC}_{70} \mathrm{BM}$ has the poor capacity of electron transfer from donor material (5) to acceptor material $\left(\mathrm{PC}_{70} \mathrm{BM}\right)$. Therefore, molecule 5 will be not mentioned in the next section (Figure 4).

The predictions (using the calculated values of $\Delta E_{L-L}$ summarized in Table 1) using Marks model display that the predicted PCE ( 9.3\%), corresponding to $\Delta E_{L-L}=0.65 \mathrm{eV}$, of 1 is in excellent agreement with the experimental value $(9.2 \%$, calculated with an experimental data $\mathrm{FF}=70.5 \%$ and $\left.V_{\mathrm{OC}}=0.97 \mathrm{~V}[14]\right)$. Interestingly, this result reveals that Marks model is a powerful tool to provide OPVs performance. Thus, we employed Marks model to predict the PCEs of three OPVs made by SMs 2, 3 and 4 with $\mathrm{PC}_{70} \mathrm{BM}$. The predicted values are found to be $\sim 12.5 \%, \sim 13.3 \%$, and $\sim 14.3 \%$, respectively. From this prediction, we reached our purpose to provide substantiation for the rational design of three novel molecules that will be more promising candidates for high-efficiency SMs OPVs materials. Even though, to further justify the high performance of the designed SMs 2-4, we have investigated the charge transfer process from donor to acceptor materials in the systems $1 / \mathrm{PC}_{70} \mathrm{BM}, 2 / \mathrm{PC}_{70} \mathrm{BM}, 3 / \mathrm{PC}_{70} \mathrm{BM}$ and $4 / \mathrm{PC}_{70} \mathrm{BM}$.

\section{Interfacial electron transfer: Marcus Theory}

One of the major challenges in designing OPVs devices is achieving maximum charge transfer at the $\mathrm{D} / \mathrm{A}$ interface, consequently increasing exciton dissociation and decreasing non radiative recombination $[65,66]$. Here we focus on the intermolecular charge transfer (interCT) excited states, because they are the excited states that present the ability of charge transfer from ground to excited states with the holes are localized on both donor and acceptor and the electrons are concentrated only on the acceptor.

The calculated electronic transitions in optical absorption of $1 /$ $\mathrm{PC}_{70} \mathrm{BM}, 2 / \mathrm{PC}_{70} \mathrm{BM}, 3 / \mathrm{PC}_{70} \mathrm{BM}$ and $4 / \mathrm{PC}_{70} \mathrm{BM}$ at TDDFT/CAMB3LYP/6-31G(d) are listed in Tables S4-S7. It is found that for each system, there is only one strong absorption peak in the low-energy region with the largest oscillator strength; $\mathrm{S}_{3}$ for $1 / \mathrm{PC}_{70} \mathrm{BM}$ and $\mathrm{S}_{2}$ for $2 / \mathrm{PC}_{70} \mathrm{BM}, 3 / \mathrm{PC}_{70} \mathrm{BM}$ and $4 / \mathrm{PC}_{70} \mathrm{BM}$. Charge density difference (CDD) maps in Figure 5 reveal that these peaks correspond to local excited (LE) transitions where electron and holes are concentrated on 1-4 similar to $\mathrm{S}_{1}$ excited states of 1-4 plotted in Table 2.

From analysis of the CDD maps of electronic transitions, we have selected the inter-CT excited states for systems $1 / \mathrm{PC}_{70} \mathrm{BM}, 3 / \mathrm{PC}_{70} \mathrm{BM}$

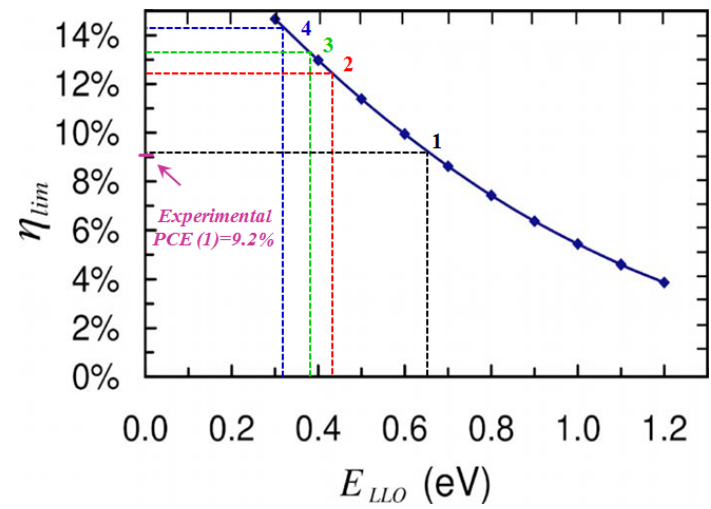

Figure 4: Practical efficiency limit $\left(\eta_{\min }\right)$ of bulk-heterojunction photovoltaic devices versus the LUMO offset $\left(\Delta E_{L-L}\right)$ (solid squares) [62]. The dashed lines show the values for the $\Delta E_{L-L}$ of 1-4 (calculated in Table 1) and the estimated PCE (\%) of the OPVs based on SMs 1-4 as donor materials. 
Citation: Khlaifia D, Mestiri T, Mabrouk L, Alimi K (2018) Theoretical Approach Towards Rational Design and Characterization of Benzo[1,2-b:5-B'] dithiophene (BDT)-Based (A-D-A) Small Molecules of Relevance for High Performance Solar Cells. J Material Sci Eng 7: 423. doi: 10.4172/2169-0022.1000423

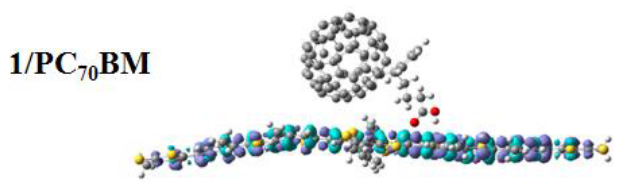

$\mathrm{S}_{3}$

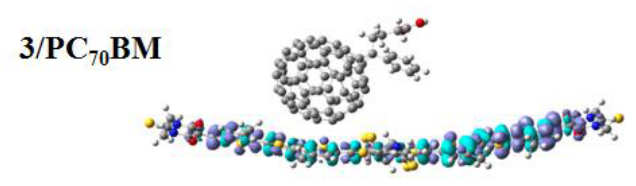

$\mathbf{S}_{2}$

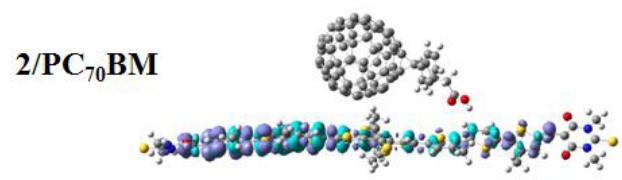

$\mathrm{S}_{2}$

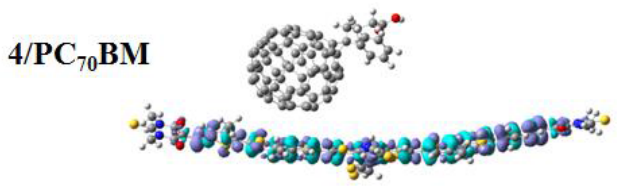

$\mathbf{S}_{2}$

Figure 5: Charge density difference maps corresponding to the dominant excited states of systems $1 / \mathrm{PC}_{70} \mathrm{BM}, 2 / \mathrm{PC} \mathrm{C}_{70} \mathrm{BM}, 3 / \mathrm{PC} \mathrm{B}_{70} \mathrm{BM}$ and $4 / \mathrm{PC} \mathrm{B}_{70} \mathrm{BM}$, where the violet and turquoise colors stand for the electron and hole, respectively.
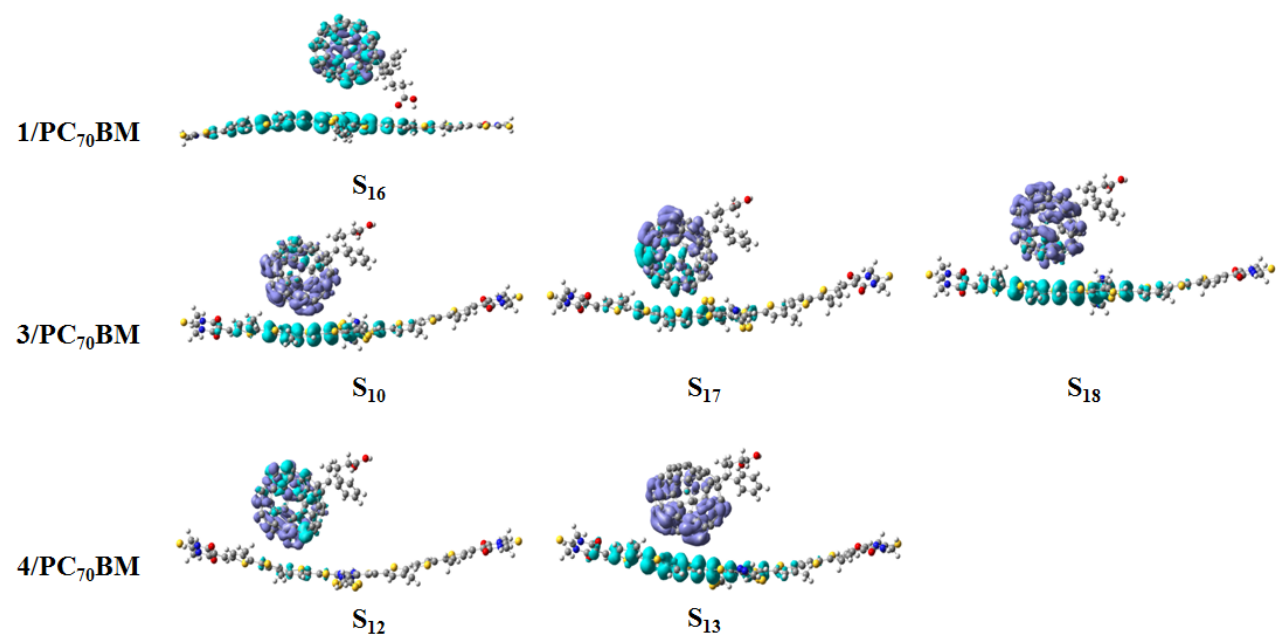

Figure 6: Charge density difference maps corresponding to inter-CT excited states of systems $1 / \mathrm{PC}_{70} \mathrm{BM}, 3 / \mathrm{PC}_{70} \mathrm{BM}$ and $4 / \mathrm{PC}_{70} \mathrm{BM}$, where the violet and turquoise colors stand for the electron and hole, respectively.

and $4 / \mathrm{PC}_{70} \mathrm{BM}$, except for $2 / \mathrm{PC}_{70} \mathrm{BM}$ which has no inter-CT excited states in the first 20 excited states. We plotted in Figure 6 the CDD maps of inter-CT excited states for the investigated heterojunctions. We deduce that $\mathrm{S}_{16}$ for $1 / \mathrm{PC}_{70} \mathrm{BM}, \mathrm{S}_{10}, \mathrm{~S}_{17}$ and $\mathrm{S}_{18}$ for $3 / \mathrm{PC}_{70} \mathrm{BM}$, and $\mathrm{S}_{12}$ and $\mathrm{S}_{13}$ for $4 / \mathrm{PC}_{70} \mathrm{BM}$ are inter-CT excited states. These excited states are not pure intermolecular charge separate excited states, since holes are also localized on acceptor material $\left(\mathrm{PC}_{70} \mathrm{BM}\right)$.

The rates of charge transfer/recombination at the $1 / \mathrm{PC}_{70} \mathrm{BM}, 3 /$ $\mathrm{PC}_{70} \mathrm{BM}$ and $4 / \mathrm{PC}_{70} \mathrm{BM}$ interfaces are computed on the basis of Marcus theory [34] as follows:

$$
k=\left|V_{D A}\right|^{2} \frac{1}{h} \sqrt{\frac{4 \pi^{3}}{\lambda k_{B} T}} \exp \left(-\frac{(\Delta G+\lambda)^{2}}{4 \lambda k_{B} T}\right)
$$

Where $V_{\mathrm{DA}}$, is the electronic coupling (charge transfer integral) between $\mathrm{D}$ and A molecules, $\lambda$, is the reorganization energy, $\Delta G$ is the free energy change during electron transfer reaction, $h$ is the Planck's constant, $k_{B}$, is the Boltzmann constant and $T$ is the temperature, (defined as $300 \mathrm{~K}$ in our calculations).

The electronic coupling between the two states $\mathrm{S}_{0}$ and $\mathrm{S}_{n}$ can be computed using the generalized Mulliken-Hush (GMH) formalism $[67,68]$ :

$$
V_{D A}=\frac{\mu_{t r} \Delta E}{\sqrt{(\Delta \mu)^{2}+4\left(\mu_{t r}\right)^{2}}}
$$

here, $\mu_{t r}$ is the calculated transition dipole moment along the $\mathrm{z}$ axis (Figure $1 \mathrm{~b}), \Delta E$ is the vertical excitation energy and $\Delta \mu$ is the dipole moment difference between the initial state $\mathrm{S}_{0}$ and $\mathrm{S}_{\mathrm{n}}$. $V_{\mathrm{DA}}$ was evaluated only for the inter-CT excited states and the calculated values of $V_{D A}^{2}$ are $3 \times 10^{-3} \mathrm{eV}$ for $1 / \mathrm{PC}_{70} \mathrm{BM}, 0.63 \mathrm{eV}$ for $3 / \mathrm{PC}_{70} \mathrm{BM}$, and 0.26 $\mathrm{eV}$ for $4 / \mathrm{PC}_{70} \mathrm{BM}$.

The reorganization energy $\lambda$ includes the internal reorganization energy $\left(\lambda_{\text {int }}\right)$ and external reorganization energy $\left(\lambda_{\text {ext }}\right)[69,70]$. The $\lambda_{\text {in }}$ arises from the change in the molecular geometry of donor (D) and acceptor (A) due to the gain or loss of electronic charge throughout electron transfer process. The $\lambda_{\text {int }}$ can be estimated with [71]:

$$
\lambda_{\mathrm{min}}=\left[E\left(A^{-}\right)-E(A)\right]+\left[E(D)-E\left(D^{+}\right)\right]
$$

where $E\left(A^{-}\right)$and $E(A)$ are the energies of the neutral acceptor at the anionic geometry and optimal ground state geometry, respectively. $E(D)$ and $E(D)$ are the energies of the cationic electron donor at the neutral geometry and optimal cation geometry, respectively. The $\lambda_{\text {ext }}$ designates the variation in the surrounding medium due to the 
Citation: Khlaifia D, Mestiri T, Mabrouk L, Alimi K (2018) Theoretical Approach Towards Rational Design and Characterization of Benzo[1,2-b:5-B'] dithiophene (BDT)-Based (A-D-A) Small Molecules of Relevance for High Performance Solar Cells. J Material Sci Eng 7: 423. doi: 10.4172/2169-0022.1000423

Page 8 of 10

\begin{tabular}{|c|c|c|c|c|c|c|c|c|}
\hline & $\lambda_{\text {int }}$ & $\lambda$ & $\left(V_{D A}\right)^{2}$ & $\mathbf{G}_{\mathrm{CR}}$ & $\mathbf{G}_{\mathrm{CT}}$ & $\mathbf{k}_{\text {inter-CR }}$ & $\mathbf{k}_{\text {inter-CT }}$ & $\mathbf{k}_{\text {inter-CTI }} \mathbf{k}_{\text {inter-CR }}$ \\
\hline $1 / \mathrm{PC}_{70} \mathrm{BM}$ & 0.28 & 0.39 & $3 \times 10^{-3}$ & -1.33 & -0.65 & $2.68 \times 10^{4}$ & $1.53 \times 10^{13}$ & $5.70 \times 10^{8}$ \\
\hline $3 / \mathrm{PC}_{70} \mathrm{BM}$ & 0.29 & 0.40 & 0.63 & -1.51 & -0.38 & $5.85 \times 10^{2}$ & $1.60 \times 10^{15}$ & $2.73 \times 10^{12}$ \\
\hline $4 / \mathrm{PC}_{70} \mathrm{BM}$ & 0.31 & 0.42 & 0.26 & -1.55 & -0.32 & $6.73 \times 10^{2}$ & $6.73 \times 10^{15}$ & $1.0 \times 10^{13}$ \\
\hline
\end{tabular}

Table 3: Calculated internal reorganization energy $\lambda_{\text {int }}(\mathrm{eV})$, total reorganization energy $\lambda(\mathrm{eV})$, square of electronic coupling $V_{D A}^{2}$ (eV), Gibbs free energy change $\Delta \mathrm{G}$ $(\mathrm{eV})$, charge recombination $k_{\text {inter-CR }}\left(\mathrm{s}^{-1}\right)$ and exciton dissociation $k_{\text {inter-CT }}\left(\mathrm{s}^{-1}\right)$ rates, and $k_{\text {int } e r-C T} / k_{\text {int } e r-C R}$ ratios of $1 / \mathrm{PC}_{61} \mathrm{BM}, 3 / \mathrm{PC}_{61} \mathrm{BM}$ and $4 / \mathrm{PC} \mathrm{B}_{61} \mathrm{BM}$ heterojunctions

electronic and nuclear polarizations effects [71-73]. However, it is confirmed that it is not easy to estimate quantitatively the $\lambda_{\text {ext }}$ in solid state. For the heterojunction $\mathrm{P} 3 \mathrm{HT} / \mathrm{PC}_{61} \mathrm{BM}$, the reorganization energy $\lambda_{\text {ext }}$ is $0.11 \mathrm{eV}$ [39], so we admit a value of $0.11 \mathrm{eV}$ for the $\lambda_{\text {ext }}$ in our calculations. The calculated total reorganization energy $\lambda=\lambda_{\text {int }}+\lambda_{\text {ext }}$ is $0.39 \mathrm{eV}$ for $1 / \mathrm{PC}_{70} \mathrm{BM}, 0.40 \mathrm{eV}$ for $3 / \mathrm{PC}_{70} \mathrm{BM}$, and $0.42 \mathrm{eV}$ for $4 /$ $\mathrm{PC}_{70} \mathrm{BM}$. As a consequence, there is little to no difference between the values of $\lambda$, which indicates that this parameter will not produce differences in the rates $k_{\text {inter-Cr }}$ and $k_{\text {inter-CR }}$ between the three systems.

During charge transfer and charge recombination process, the free energy change $\Delta G=\Delta G_{c T}$ and $\Delta G_{c R}$, respectively. Referring to eqn. (2), a potential donor molecule would show high $\left|\Delta G_{c k}\right|$ and small $\left|\Delta G_{c r}\right|$ to promote efficient exciton dissociation and slow charge recombination. The $\Delta G_{c R}$ can be evaluated by [74]:

$$
\Delta G_{c R}=E_{P P}(D)-E_{E A}(A)
$$

here, the $E_{p D}(D)$ is the ionization potential of the donor and $E_{\varepsilon A}(A)$ is the electron affinity of the acceptor. These quantities are considered to be respectively the HOMO energy of donor and LUMO energy of the acceptor [75]. The computed values of $\Delta G_{c R}$ are -1.33, -1.51, and -1.55 $\mathrm{eV}$ for $1 / \mathrm{PC}_{70} \mathrm{BM}, 3 / \mathrm{PC}_{70} \mathrm{BM}$ and $4 / \mathrm{PC}_{70} \mathrm{BM}$, respectively. The $\Delta G_{c r}$ can be evaluated by the Rehm-Weller equation [76]:

$$
\Delta G_{c T}=-\Delta G_{c R}-\Delta E_{0-0}-E_{b}
$$

where, $\Delta E_{0-0}$ is the lowest excited state energy of the donor and $E_{b}$ is the exciton binding energy. However, $E_{b}$ is defined as the energy difference between the electronic band-gap and the first singlet excitation energy $\Delta E_{0-0}[67,68,71,74-76]$ :

$$
E_{b}=\Delta E_{H-L}-\Delta E_{0-0}
$$

Based on equation (7), $\Delta G_{c T}$ can be expressed as:

$$
\Delta G_{C T}=-\Delta_{G R}-\Delta E_{H-L}
$$

We calculated the $\Delta G_{c r}$ of $1 / \mathrm{PC}_{70} \mathrm{BM}, 3 / \mathrm{PC}_{70} \mathrm{BM}$ and $4 / \mathrm{PC}_{70} \mathrm{BM}$ to be $-0.86,-0.38$ and $-0.32 \mathrm{eV}$, respectively. The result indicates that the charge transfer in $4 / \mathrm{PC}_{70} \mathrm{BM}$ is thermodynamically more favorable as compared to those for the other systems.

Table 3 shows all the computed Marcus parameters for the 1/ $\mathrm{PC}_{70} \mathrm{BM}, 3 / \mathrm{PC}_{70} \mathrm{BM}$, and $4 / \mathrm{PC}_{70} \mathrm{BM}$ interfaces. Obviously, the calculated ratios $k_{\text {inter-CT }}, k_{\text {inter-CR }}$ of $3 / \mathrm{PC}_{70} \mathrm{BM}$, and $4 / \mathrm{PC}_{70} \mathrm{BM}$ are $\sim 10^{4}$ times higher than that of $1 / \mathrm{PC}_{70} \mathrm{BM}$. This result reveals that $\mathrm{BHJ}$ devices based on $3 / \mathrm{PC}_{70} \mathrm{BM}$ and $4 / \mathrm{PC}_{70} \mathrm{BM}$ have much stronger effective exciton dissociation and then higher $J_{\mathrm{SC}}$ than that based on $1 / \mathrm{PC}_{70} \mathrm{BM}$.

However, we can notice that the performance of SM 1 remains acceptable (9.2\%) despite its low $k_{\text {inter-CT }}$ compared to those of SMs 3 and 4, implying that the device performance is not only driven by the interfacial charge transfer rate. Indeed, to optimize the $\mathrm{BHJ}$ device efficiency, it is important to find an efficient D/A combination in terms of electronic energy level, optical absorption, exciton lifetime, charge carrier mobility, solubility and thickness of the active layer [64,77]. All these factors impact OPV device efficiency. In that context, Cui et al.
[14] have found that SM 1 is a very attractive donor candidate for the fabrication of $\mathrm{BHJ}$ device with high PCE of 9.2\% because of its good solution processability, crystalline structure, low lying HOMO energy, broad absorption profile and higher hole mobility.

\section{Conclusions}

To summarize, we have carried out DFT and TDDFT calculations on the geometric, electronic and photophysical properties of new designed (A-D-A) small molecules based on the experimental system BDTT-S-TR (1). Our simulated results reveal that the designed SMs 2-5 possess quasi-planar geometries, well-matched energy levels and broad absorption in the UV-visible range. From these molecules, the designed molecules 2-4 display suitable $\Delta E_{L-L}$ values for an effective charge transfer with $\mathrm{PC}_{70} \mathrm{BM}$ as an acceptor material and large $V_{\mathrm{OC}}$ values. Thus, we predicted the PCEs of the OPVs based on 1-4/PC ${ }_{70} \mathrm{BM}$ using Marks model. The predicted PCE of OPV based on $1 / \mathrm{PC}_{70} \mathrm{BM}$ is approximately $\sim 9.3 \%$, which is in good agreement with the measured PCE equal to $9.2 \%$. Interestingly, this result is of great interest for predicting the efficiencies of $\mathrm{BHJ}$ devices based on $2-4 / \mathrm{PC}_{70} \mathrm{BM}$. The predictions using Marks model show significant improvement in PCEs of OPVs based on $2-4 / \mathrm{PC}_{70} \mathrm{BM}$ compared to $1 / \mathrm{PC}_{70} \mathrm{BM}$. Next, an in depth theoretical investigation of the hopping rates $k_{\text {inter-CT }}$ and $\boldsymbol{k}_{\text {inter-CR }}$ and the ratios $\boldsymbol{k}_{\text {inter-CT }} \boldsymbol{k}_{\text {inter-CR }}$ in the blends $1 / \mathrm{PC}_{70} \mathrm{BM}$, $3 / \mathrm{PC}_{70} \mathrm{BM}$, and $4 / \mathrm{PC}_{70} \mathrm{BM}$ was carried out. The computational results show that the $\mathrm{BHJ}$ devices based on $3 / \mathrm{PC}_{70} \mathrm{BM}$ and $4 / \mathrm{PC}_{70} \mathrm{BM}$ present fast charge transfer with a ratio $\boldsymbol{k}_{\text {inter-CT }} / \boldsymbol{k}_{\text {inter-CR }} \sim 10^{4}$ times higher than that of $1 / \mathrm{PC}_{70} \mathrm{BM}$, which favors effective exciton dissociation and then an improvement in $J_{\mathrm{SC}}$. These results suggest that the designed small molecules 3 and 4 will be attractive candidates for high-efficiency SMs OPVs materials. Finaly, it is hoped that this computational study may stimulate experimentalists to synthesize and study these new small molecules; structural parameters, optical and photovoltaic properties were computed, which will facilitate future experimental work.

\section{Acknowledgment}

All calculations were done in the CCIPL (Center for Calculations, Region Pays de la Loire Nantes, France).

\section{References}

1. Tang CW (1986) Two-layer organic photovoltaic cell. Applied Physics Letters 48: $183-185$

2. Yassar A, Miozzo L, Gironda R, Horowitz G (2013) Rod-coil and all-conjugated block copolymers for photovoltaic applications. Progress in Polymer Science 38: 791-844

3. Yi Y, Coropceanu V, Brédas JL (2009) Exciton-dissociation and chargerecombination processes in pentacene/C60 solar cells: theoretical insight into the impact of interface geometry. Journal of the American Chemical Society 131: 15777-15783.

4. Mayukh M, Jung IH, He F, Yu L (2012) Incremental optimization in donor polymers for bulk heterojunction organic solar cells exhibiting high performance. Journal of Polymer Science Part B: Polymer Physics 50: 1057-1070.

5. Rita Narayan M, Singh J (2013) Study of the mechanism and rate of exciton dissociation at the donor-acceptor interface in bulk-heterojunction organic solar cells. Journal of Applied Physics 114: 073510. 
Citation: Khlaifia D, Mestiri T, Mabrouk L, Alimi K (2018) Theoretical Approach Towards Rational Design and Characterization of Benzo[1,2-b:5-B'] dithiophene (BDT)-Based (A-D-A) Small Molecules of Relevance for High Performance Solar Cells. J Material Sci Eng 7: 423. doi: 10.4172/2169-0022.1000423

6. Castet F, D'Avino G, Muccioli L, Cornil J, Beljonne D (2014) Charge separation energetics at organic heterojunctions: on the role of structural and electrostatic disorder. Physical Chemistry Chemical Physics 16: 20279-20290.

7. Gautam P, Sharma R, Misra R, Keshtov ML, Kuklin SA, et al. (2017) Donoracceptor-acceptor (D-A-A) type 1, 8-naphthalimides as non-fullerene smal molecule acceptors for bulk heterojunction solar cells. Chemical Science 8 2017-2024.

8. Etxebarria I, Ajuria J, Pacios R (2015) Solution-processable polymeric solar cells: A review on materials, strategies and cell architectures to overcome $10 \%$ Organic Electronics 19: 34-60.

9. Li M, Ni W, Wan X, Zhang Q, Kan B, et al. (2015) Benzo [1, 2-b: 4, 5-b'] dithiophene (BDT)-based small molecules for solution processed organic solar cells. Journal of Materials Chemistry A 3: 4765-4776.

10. Dou L, Liu Y, Hong Z, Li G, Yang Y (2015) Low-bandgap near-IR conjugated polymers/molecules for organic electronics. Chemical Reviews 115: 12633 12665

11. Li Y (2012) Molecular design of photovoltaic materials for polymer solar cells toward suitable electronic energy levels and broad absorption. Accounts of Chemical Research 45: 723-733.

12. He Z, Xiao B, Liu F, Wu H, Yang Y, et al. (2015) Single-junction polymer solar cells with high efficiency and photovoltage. Nature Photonics 9: 174-179.

13. Ouyang X, Peng R, Ai L, Zhang X, Ge Z (2015) Efficient polymer solar cells employing a non-conjugated small-molecule electrolyte. Nature Photonics 9 : 520-524.

14. Cui C, Guo X, Min J, Guo B, Cheng X, et al. (2015) High-Performance Organic Solar Cells Based on a Small Molecule with Alkylthio-Thienyl-Conjugated Side Chains without Extra Treatments. Advanced Materials 27: 7469-7475.

15. Kan B, Li M, Zhang Q, Liu F, Wan X, et al. (2015) A series of simple oligomerlike small molecules based on oligothiophenes for solution-processed solar cells with high efficiency. Journal of the American Chemical Society 137: 38863893.

16. Sun Y, Welch GC, Leong WL, Takacs CJ, Bazan GC, et al. (2012) Solutionprocessed small-molecule solar cells with $6.7 \%$ efficiency. Nature Materials 11 $44-48$

17. Gautam P, Misra R, Koukaras EN, Sharma A, Sharma GD (2015) Donoracceptor-acceptor-donor small molecules for solution processed bulk heterojunction solar cells. Organic Electronics 27: 72-83.

18. Ratier B, Nunzi JM, Aldissi M, Kraft TM, Buncel E (2012) Organic solar cell materials and active layer designs-improvements with carbon nanotubes: a review. Polymer International 61: 342-354.

19. Park SH, Roy A, Beaupré S, Cho S, Coates N, et al. (2009) Bulk heterojunction solar cells with internal quantum efficiency approaching $100 \%$. Nature Photonics 3: 297-302.

20. Wang M, Hu X, Liu P, Li W, Gong X, et al. (2011) Donor-acceptor conjugated polymer based on naphtho [1, 2-c: $5,6-c]$ bis $[1,2,5]$ thiadiazole for highperformance polymer solar cells. Journal of the American Chemical Society 133: 9638-9641.

21. Zhang Y, Zou J, Cheuh CC, Yip HL, Jen AKY (2012) Significant improved performance of photovoltaic cells made from a partially fluorinated cyclopentadithiophene/benzothiadiazole conjugated polymer. Macromolecules 45: 5427-5435.

22. Li SB, Duan YA, Geng Y, Li HB, Zhang JZ, et al. (2014) A designed bithiopheneimide-based conjugated polymer for organic photovoltaic with ultrafast charge transfer at donor/PC71BM interface: theoretical study and characterization. Physical Chemistry Chemical Physics 16: 25799-25808.

23. Liu Y, Chen CC, Hong Z, Gao J, Yang YM, et al. (2013) Solution-processed small-molecule solar cells: breaking the $10 \%$ power conversion efficiency. Scientific Reports 3: 3356.

24. Kan B, Zhang Q, Li M, Wan X, Ni W, et al. (2014) Solution-processed organic solar cells based on dialkylthiol-substituted benzodithiophene unit with efficiency near $10 \%$. Journal of the American Chemical Society 136: 1552915532

25. He Z, Zhong C, Su S, Xu M, Wu H, et al. (2012) Enhanced power-conversion efficiency in polymer solar cells using an inverted device structure. Nature Photonics 6: 591-597.
26. Guo X, Zhang M, Ma W, Ye L, Zhang S, et al. (2014) Enhanced Photovoltaic Performance by Modulating Surface Composition in Bulk Heterojunction Polymer Solar Cells Based on PBDTTT-C-T/PC71BM. Advanced Materials 26: 4043-4049.

27. Ye L, Zhang S, Zhao W, Yao H, Hou J, (2014) Highly Efficient 2D-Conjugated Benzodithiophene-Based Photovoltaic Polymer with Linear Alkylthio Side Chain. Chem Mater 26: 3603-3605.

28. Liao S-H, Jhuo H-J, Cheng Y-S, Chen S-A (2013) Fullerene Derivative-Doped Zinc Oxide Nanofilm as the Cathode of Inverted Polymer Solar Cells with LowBandgap Polymer (PTB7-Th) for High Performance. Adv Mater 25: 4766-4771.

29. Min J, Kwon OK, Cui C, Park J-H, Wu Y, et al. (2016) High performance allsmall-molecule solar cells: engineering the nanomorphology via processing additives. J Mater Chem A 4:14234-14240.

30. Yin X, An Q, Yu J, Guo F, Geng Y, et al. (2016) Side-chain Engineering of Benzo[1,2-b:4,5-b']dithiophene Core-structured Small Molecules for HighPerformance Organic Solar Cells. Sci Rep 6.

31. Min J, Cui C, Heumueller T, Fladischer S, Cheng X, et al. (2016) Side-Chain Engineering for Enhancing the Properties of Small Molecule Solar Cells: A Trade-off Beyond Efficiency. Adv Energy Mater 6: 1600515

32. Wang T, Pearson AJ, Lidzey DG (2013) Correlating molecular morphology with optoelectronic function in solar cells based on low band-gap copolymer:fullerene blends. J Mater Chem C 1:7266-7293.

33. Cho H-H, Kang TE, Kim K-H, Kang H, Kim HJ, et al. (2012) Effect of Incorporated Nitrogens on the Planarity and Photovoltaic Performance of Donor-Accepto Copolymers. Macromolecules 45: 6415-6423.

34. Marcus RA (1993) Elektronentransferreaktionen in Der Chemie-Theorie Und Experiment (Nobel-Vortrag). Angew Chem 105: 1161-1172.

35. Barbara PF, Meyer TJ, Ratner MA. Contemporary Issues in Electron Transfe Research. J Chem Phys 100: 13148-13168.

36. Pandey L, Risko C, Norton JE, Brédas J-L (2012) Donor-Acceptor Copolymers of Relevance for Organic Photovoltaics: A Theoretical Investigation of the Impact of Chemical Structure Modifications on the Electronic and Optical Properties. Macromolecules 45: 6405-6414.

37. Liu X, He R, Shen W, Li M (2014) Molecular design of donor-accepto conjugated copolymers based on $\mathrm{C}$-, $\mathrm{Si}$ - and $\mathrm{N}$-bridged dithiophene and thienopyrroledione derivatives units for organic solar cells. J of Power Sources 2014;245:217-23.

38. Duan Y-A, Geng Y, Li H-B, Jin J-L, Wu Y, et al. (2013) Theoretical characterization and design of small molecule donor material containing naphthodithiophene central unit for efficient organic solar cells. J Comput Chem 34: 1611-1619.

39. Liu T, Troisi A (2011) Absolute Rate of Charge Separation and Recombination in a Molecular Model of the P3HT/PCBM Interface. J Phys Chem C 115: 24062415.

40. Perdew JP, Burke K, Wang Y (1996) Generalized gradient approximation for the exchange-correlation hole of a many-electron system. J Am Chem Soc 54 16533-16539.

41. Becke AD (1993) Density-functional thermochemistry. III. The role of exact exchange. J Chem Phys 98: 5648-5652.

42. Adamo C, Barone V (1999) Toward Reliable Density Functional Methods without Adjustable Parameters: The PBE0 Model. J Chem Phys 110: 61586170 .

43. Barone V Cossi M, Tomasi J (1997) A new definition of cavities for the computation of solvation free energies by the polarizable continuum model. $J$ Chem Phys 107: 3210-3121.

44. Cossi M, Scalmani G, Rega N, Barone V (2002) New developments in the polarizable continuum model for quantum mechanical and classical calculations on molecules in solution. J Chem Phys 117: 43-54.

45. Graham KR, Cabanetos C, Jahnke JP, Idso MN, El Labban A, et al. (2014) Importance of the donor: fullerene intermolecular arrangement for highefficiency organic photovoltaics. J Am Chem Soc 136: 9608-9618.

46. Leng C, Qin H, Si Y, Zhao Y (2014) Theoretical Prediction of the Rate Constants for Exciton Dissociation and Charge Recombination to a Triple State in PCPDTBT with Different Fullerene Derivatives. J Phys Chem C 118: 1843-1855. 
Citation: Khlaifia D, Mestiri T, Mabrouk L, Alimi K (2018) Theoretical Approach Towards Rational Design and Characterization of Benzo[1,2-b:5-B'] dithiophene (BDT)-Based (A-D-A) Small Molecules of Relevance for High Performance Solar Cells. J Material Sci Eng 7: 423. doi: 10.4172/2169-0022.1000423

Page 10 of 10

47. Yanai T, Tew DP, Handy NC (2004) A new hybrid exchange-correlation functional using the Coulomb-attenuating method (CAM-B3LYP). Chem Phys Lett 393: 51-57.

48. Li Y, Qi D, Song P, Ma F (2014) Fullerene-Based Photoactive Layers for Heterojunction Solar Cells: Structure, Absorption Spectra and Charge Transfer Process. Materials 8: 42-56.

49. Lu T, Chen F (2012) Multiwfn: A multifunctional wavefunction analyzer. J Comput Chem 33: 580-592.

50. http://multiwfn.codeplex.com.

51. Frisch MJ, Trucks GW, Schlegel HB, Scuseria Robb MA, Cheeseman JR, et al (2009) Gaussian 09, Revision A.02, Gaussian, Inc., Wallingford CT.

52. Khlaifia D, Ewels CP, Massuyeau F, Chemek M, Faulques E, et al. (2016) Unraveling the real structures of solution-based and surface-bound poly (3hexylthiophene) (P3HT) oligomers: a combined theoretical and experimental study. RSC Adv 6: 56174-56182.

53. Fei Z, Boufflet P, Wood S, Wade J, Moriarty J, et al. (2015) Influence of Backbone Fluorination in Regioregular Poly(3-alkyl-4-fluoro)thiophenes. J Am Chem Soc 137: 6866-6879.

54. Risko C, McGehee MD, Brédas J-L (2011) A quantum-chemical perspective into low optical-gap polymers for highly-efficient organic solar cells. Chem Sc 2: $1200-1218$.

55. Zhang G, Musgrave CB (2007) Comparison of DFT Methods for Molecular Orbital Eigenvalue Calculations. The Journal of Physical Chemistry A 111: 1554-1561.

56. Frost JM, Faist MA, Nelson J (2010) Energetic Disorder in Higher Fullerene Adducts: A Quantum Chemical and Voltammetric Study. Adv Mater 22: 48814884

57. Zhou H, Yang L, You W (2012) Rational Design of High Performance Conjugated Polymers for Organic Solar Cells. Macromolecules 45: 607-632.

58. Kim B-G, Ma X, Chen C, le Y, Coir EW, et al. (2013) Energy Level Modulation of HOMO, LUMO, and Band-Gap in Conjugated Polymers for Organic Photovoltaic Applications. Adv Funct Mater 23: 439-445.

59. Oliveira EF, Lavarda FC (2016) Copolymers with similar comonomers: Tuning frontier orbital energies for application in organic solar cells. Polymer Engineering and Science 56: 479-487.

60. Goldey MB, Reid D, de Pablo J, Galli G (2016) Planarity and multiple components promote organic photovoltaic efficiency by improving electronic transport. Phys Chem Chem Phys 18: 31388-31399.

61. Son HJ, Carsten B, Jung IH, Yu L (2012) Overcoming efficiency challenges in organic solar cells: rational development of conjugated polymers. Energy Environ Sci 5: 8158.

62. Servaites JD, Ratner MA, Marks TJ (2009) Practical efficiency limits in organic photovoltaic cells: Functional dependence of fill factor and external quantum efficiency. Appl Phys Lett 95: 163302.
63. Scharber MC, Mühlbacher D, Koppe M, Denk P, Waldauf C, et al. (2006) Design Rules for Donors in Bulk-Heterojunction Solar Cells-Towards $10 \%$ Energy-Conversion Efficiency. Adv Mater 18: 789-794.

64. Janssen RAJ, Nelson J (2013) Factors Limiting Device Efficiency in Organic Photovoltaics. Adv Mater 25: 1847-1858.

65. Yost SR, Hontz E, McMahon DP, Van Voorhis T (2014) Electronic and Optica Properties at Organic/Organic Interfaces in Organic Solar Cells. Top Curr Chem 352: 103-150.

66. Solanki A, Wu B, Salim T, Lam YM, Sum TC (2015) Correlation between blend morphology and recombination dynamics in additive-added P3HT:PCBM solar cells. Phys Chem Chem Phys 17: 26111-26120.

67. Voityuk AA (2006) Estimation of electronic coupling in m-stacked donor-bridgeacceptor systems: Correction of the two-state model. J Chem Phys 124: 64505

68. Hsu C-P (2009) The Electronic Couplings in Electron Transfer and Excitation Energy Transfer. Acc Chem Res 42: 509-518.

69. Song P, Li Y, Ma F, Pullerits T, Sun M (2013) External Electric Field-Dependent Photoinduced Charge Transfer in a Donor-Acceptor System for an Organic Solar Cell. J Phys Chem C 117: 15879-15889.

70. Lemaur V, Steel M, Beljonne D, Brédas J-L, Cornil J (2005) Photoinduced Charge Generation and Recombination Dynamics in Model Donor/Acceptor Pairs for Organic Solar Cell Applications: A Full Quantum-Chemical Treatment. J Am Chem Soc 127: 6077-6086.

71. Li Y, Pullerits T, Zhao M, Sun M (2011) Theoretical Characterization of the PC 60 BM:PDDTT Model for an Organic Solar Cell. J Phys Chem C 115: 2186521773.

72. Tang S, Zhang J (2011) Rational Design of Organic Asymmetric Donors D1-AD2 Possessing Broad Absorption Regions and Suitable Frontier Molecular Orbitals to Match Typical Acceptors toward Solar Cells. J Phys Chem A 115: 5184-5191.

73. Kawatsu T, Coropceanu V, Ye A, Brédas J-L (2008) Quantum-Chemical Approach to Electronic Coupling: Application to Charge Separation and Charge Recombination Pathways in a Model Molecular Donor-Acceptor System for Organic Solar Cells. The J Phys Chem C 112: 3429-3433.

74. Kavarnos GJ, Turro NJ (1986) Photosensitization by reversible electron transfer: theories, experimental evidence, and examples. Chem Rev 86: 401449 .

75. Zhang X, Chi L, Ji S, Wu Y, Song P, et al. (2009) Rational Design of d-PeT Phenylethynylated-Carbazole Monoboronic Acid Fluorescent Sensors for the Selective Detection of $\alpha$-Hydroxyl Carboxylic Acids and Monosaccharides. J Am Chem Soc 131: 17452-17463.

76. Scholes GD, Rumbles G (2006) Excitons in nanoscale systems. Nat Mater 5 683-696.

77. Yong X, Zhang JP (2013) Theoretical investigations for organic solar cells Materials Technology 28: 40-64. 